\title{
Polypyrrole Functionalized Graphene Oxide Accelerated Zinc Phosphate Coating under Low-Temperature
}

Qingsong Zhu, ${ }^{1,2}$ Jingguang Liu, ${ }^{3}$ Xin Wang, ${ }^{1,4}$ Yuxiang Huang, ${ }^{2}$ Ying Ren, ${ }^{2}$ Weiqiang Song, ${ }^{2}$ Chenzhong Mu, ${ }^{5}$ Xianhu Liu, ${ }^{1, *}$ Fengchun $\mathrm{Wei}^{2, *}$ and Chuntai $\mathrm{Liu}^{1, *}$

\begin{abstract}
Zinc phosphate coating, as an effective and fast anticorrosion technique for the metals, have been developed rapidly in recent years. However, it is still a challenge to synthesize a low energy, environmentally friendly and efficient accelerator through a facile method. Herein, as a new accelerator, polypyrrole (PPy) functionalized graphene oxide (GO-PPy) nanocomposites were prepared by in-situ process to grow PPy film on GO surface, Incorporation of GO-PPy into phosphate baths accelerated the phosphating process of phosphate coating and promoted the nucleation and growth of phosphate crystals, achieving stronger corrosion resistance, which were confirmed by electrochemical measures and morphologies characteristic of the phosphate coating. Additionally, when the concentration of GO-PPy in the phosphate baths reached up $1.2 \mathrm{~g} / \mathrm{L}$, the phosphate coating possessed the most compact and uniform phosphate crystals and the best corrosion protection performance. Finally, the special mechanism of the phosphate process was discussed. This work introduces a new, low-energy, facile, environmentally friendly and alternative accelerator for the preparation of phosphate coatings.
\end{abstract}

Keywords: Phosphate coating; Corrosion protection; Accelerate; Phosphate crystals.

Received:7 July 2020; Accepted: 3 September 2020.

Article type: Research article.

\section{Introduction}

The extremely high environmental and economic impact on corrosion of metal substrate arouses large scientific interest to overcome this problem and require an extremely high environmental and economic transdisciplinary method. ${ }^{[1,2]}$ One of the easiest and most common approaches for preventing metals from corrosion is the application of various coatings. ${ }^{[3-4]}$ Zinc phosphate coating, for example, is commonly applied during drawing and extrusion of various metals because of its low cost and barrier function. ${ }^{[5]}$ Additionally, zinc phosphate coating can not only prevent

\footnotetext{
${ }^{1}$ The Key Laboratory of Material Processing and Mold of Ministry of Education, National Engineering Research Center for Advanced Polymer Processing Technology, Zhengzhou University, Zhengzhou 450002, PR China

${ }^{2}$ College of Materials Science and Engineering, Henan University of Technology, Zhengzhou 450001, PR China.

${ }^{3}$ Jier Machine-Tool Group Co, LTD, Jinan250000, PR China.

${ }^{4}$ Institute of Polymer Materials, Friedrich-Alexander University ErlangenNuremberg, Martensstr. 7, 91058 Erlangen, Germany 5 State Key Laboratory of Special Functional Waterproof Materials, Beijing Oriental Yuhong Waterproof Technology Co., Ltd, Beijing 100123, China.

*E-mail:xianhu.liu@zzu.edu.cn (X. Liu),ctliu@zzu.edu.cn (C. Liu) and fengchun_wei@haut.edu.cn (F.wei).
}

metal corrosion but also improve organic coatings' adhesion ability on the metal substrate, which are of great benefit to its practical industrial application. ${ }^{[6]}$ Unfortunately, traditional phosphating process needs to be carried out at high temperature such as $90-98^{\circ} \mathrm{C}$, and it is extremely time consuming, accounting for enormous energy consumption..$^{[7-9]}$

Thus, appropriate temperature for phosphating process has been of importance as a result of low energy consumption. However, phosphating process at low temperature is extremely slow and needed to be promoted by specialized materials such as nitrides, nitrates, and chlorates. Thus, these traditional accelerators validly reduce the phosphating time but are extremely unhealthy to human health and environment. ${ }^{[10,11]}$ Therefore, the environmental protection agency had considered those accelerators as harmful to the human. Many researchers have attempted to develop new accelerators. ${ }^{[12,13]}$ Environmental-friendly and effective accelerators are still urgently needed to upgrade traditional accelerators.

Graphene oxide (GO) produces stable dispersion in many polar and nonpolar solvents including water owing to various oxygenated functional groups, and is thus the most important and widely used medium for many industrial applications. ${ }^{[14,15]}$ 
Researches confirmed that GO could prominently enhance the resistance of coatings because of its excellent impermeability to corrosive media. ${ }^{[16,17]}$ Zhang et al. incorporated GO into phosphating bath, and investigated its effect on corrosion resistance and microstructure of phosphate coating. This paper showed that GO, as a new accelerator, effectively speeded up phosphating process, and enhanced the corrosion protection performance of phosphate coatings. ${ }^{[18]}$ However, the corresponding impedance modulus of zinc phosphate coatings was very low. In addition, polypyrrole (PPy) has become the most studied conducting polymers owing to its easy synthesis, nontoxicity and good stability. Wang et al. researched the addition of PPy intercalated graphene into epoxy coating and showed a synergistic protection on the metal substrate. ${ }^{[19]}$ Moreover, hydrophilic PPy functionalized GO could improve the dispersion ability of the agglomerated GO in many polar and nonpolar solvents owing to the increase of interlayer spacing, as a result of more uniform nanosheets absorbed on the surface of mild steel compared to GO nanosheets. In view of those, using GO-PPy as an accelerator to speed up phosphating process and then adding GO-PPy into the phosphate bath have been hardly studied.

Herein, this is the first report of concerning the possibility of GO-PPy as a fast, available accelerator to speed up the phosphating progress of phosphate coating. GO-PPy was synthesized by in-situ process to grow PPy film on the surface of GO. Thus, the GO-PPy was added into conventional phosphate bath to fabricate zinc phosphate coating on the surface of the mild steel. Potentiodynamic polarization and electrochemical impedance spectroscopy (EIS) were employed to assess the corrosion protection property of phosphate coating. X-ray diffraction (XRD) and field emission scanning electron microscope (FESEM) were used to characterize the chemical composition and morphological characteristic of phosphate coating. Finally, the phosphating mechanism of phosphate coating with GO-PPy in phosphating bath was discussed based on the above experimental results.

\section{Experimental}

\subsection{Synthesis of GO-PPy}

GO-PPy composites were prepared according to our previous reports ${ }^{[20,21]}$ Briefly, these composites were prepared by in-situ polymerization of Py on the surface of GO.

\subsection{Fabrication of phosphate coating}

Mild steel pans with the dimension of $120 \mathrm{~mm} \times 50 \mathrm{~mm} \times 0.28$ $\mathrm{mm}$ were used as the substrate of zinc phosphate coating, and these chemical composition (wt $\%$ ) were $\leq 0.22 \mathrm{C}, \leq 0.34 \mathrm{Si}$, $\leq 0.045 \mathrm{P}, \leq 0.05 \mathrm{~S}, \leq 0.70 \mathrm{Mn}$ and blance $\mathrm{Fe}$, mild steel pans were first grinded with $200,600,1000$ grit $\mathrm{SiC}$ sand paper to remove oxide layer, respectively. Then, these mild steel pans were immersed in $10 \mathrm{wt} \% \mathrm{NaOH}$ solution at $40{ }^{\circ} \mathrm{C}$ for 10 minutes to remove all alkali. These degreasing mild steel pans were rinsed with ethanol solution and dried to eliminate excess $\mathrm{NaOH}$. After that, mild steel pans were exposed to $150 \mathrm{~mL}$ of phosphating bath at $40{ }^{\circ} \mathrm{C}$ for $20 \mathrm{~min}$. The chemical composition of phosphate baths is depicted in Table 1. After the completing phosphating, the mild steel pans were rinsed with ethanol and dried. The concentration of GO in phosphating bath was $1.2 \mathrm{~g} / \mathrm{L}$, and the resultant specimen was named as GO-1.2. While the concentrations of GO-PPy nanocomposites in phosphating solution were $0,0.8,1.0,1.2$, and $1.6 \mathrm{~g} / \mathrm{L}$, respectively. The resultant specimens were named as BP, GP-0.8, GP-1.0, GP-1.2, and GP-1.6, respectively.

Table 1. Chemical composition of the phosphating baths.

\begin{tabular}{cccccc}
\hline & $\mathrm{Zn}\left(\mathrm{H}_{2} \mathrm{PO}_{4}\right)_{2}$ & $\mathrm{Zn}\left(\mathrm{NO}_{3}\right)_{2}$ & $\mathrm{H}_{3} \mathrm{PO}_{4}$ & $\mathrm{GO}$ & GO-PPy \\
\hline $\mathrm{BP}$ & $55 \mathrm{~g} / \mathrm{L}$ & $60 \mathrm{~g} / \mathrm{L}$ & $8 \mathrm{~g} / \mathrm{L}$ & & \\
$\mathrm{GO} 1.2$ & $55 \mathrm{~g} / \mathrm{L}$ & $60 \mathrm{~g} / \mathrm{L}$ & $8 \mathrm{~g} / \mathrm{L}$ & 1.2 & \\
$\mathrm{GP}-0.8$ & $55 \mathrm{~g} / \mathrm{L}$ & $60 \mathrm{~g} / \mathrm{L}$ & $8 \mathrm{~g} / \mathrm{L}$ & $\mathrm{g} / \mathrm{L}$ & $0.8 \mathrm{~g} / \mathrm{L}$ \\
$\mathrm{GP}-1.0$ & $55 \mathrm{~g} / \mathrm{L}$ & $60 \mathrm{~g} / \mathrm{L}$ & $8 \mathrm{~g} / \mathrm{L}$ & & $1.0 \mathrm{~g} / \mathrm{L}$ \\
$\mathrm{GP}-1.2$ & $55 \mathrm{~g} / \mathrm{L}$ & $60 \mathrm{~g} / \mathrm{L}$ & $8 \mathrm{~g} / \mathrm{L}$ & & $1.2 \mathrm{~g} / \mathrm{L}$ \\
$\mathrm{GP}-1.6$ & $55 \mathrm{~g} / \mathrm{L}$ & $60 \mathrm{~g} / \mathrm{L}$ & $8 \mathrm{~g} / \mathrm{L}$ & & $1.6 \mathrm{~g} / \mathrm{L}$ \\
\hline
\end{tabular}

\subsection{Characterization}

Morphologies of phosphate coatings were characterized by FESEM (an Inspect F50 Scanning Electron Microscope). The crystalline structure and composition of phosphate coating were analyzed by XRD (Bruker D8 Advance). The corrosion protection property of phosphate coatings was evaluated by electrochemical test. All measurements were conducted by the electrochemical workstation (RST5200F, Suzhou Ruisitai Instrument Technology Co., Ltd.). The geometric area of the working electrode was $12 \mathrm{~cm}^{2}$, which was connected with the electrolytic solution ( $3.5 \mathrm{wt} \% \mathrm{NaCl}$ solution). The polarization plots were collected via a $1 \mathrm{mV} / \mathrm{s}$ scan rate. EIS tests were conducted with the frequency range of $100 \mathrm{kHz}-0.01 \mathrm{~Hz}$ using $5 \mathrm{mV}$ amplitude with alternating current signal.

\section{Results and discussion}

\subsection{Potentiodynamic polarization characterization}

The potentiodynamic polarization curves are shown in Fig. 1 and polarization parameters are listed in Table 2, respectively. In general, a material with a higher corrosion potential $\left(E_{\text {corr }}\right)$ and a lower $i_{\text {corr }}$ (corrosion current density) is held to possess a lower tendency of oxidation and corrosion and therefore higher corrosion resistance performance. ${ }^{[18]}$ From Fig. 1 and Table 2, $E_{\text {corr }}$ for BP and GO-1.2 were -623 and $-590 \mathrm{mV}$, and that for GP-0.8, GP-1.0, GP-1.2 and GP-1.6 were -561, 574, 564 and $608 \mathrm{mV}$, respectively. This indicated that $E_{\text {corr }}$ for GO-1.2 raised $33 \mathrm{mV}$ compared to that of BP, and $E_{\text {corr }}$ for GP-0.8 raised 62 $\mathrm{mV}$ compared to that of BP. Meanwhile, $i_{\text {corr }}$ for BP and GO-1.2 were 5.72 and $5.16 \mu \mathrm{A} / \mathrm{cm}^{2}$, and that for GP-0.8, GP-1.0, GP1.2 and GP-1.6 were 2.94, 3.16, 3.79 and $3.91 \mu \mathrm{A} / \mathrm{cm}^{2}$, respectively. This indicated that $i_{\text {corr }}$ for GO-1.2 was decreased to $0.56 \mu \mathrm{A} / \mathrm{cm}^{2}, i_{\text {corr }}$ for GP- 0.8 decreased to $1.81 \mu \mathrm{A} / \mathrm{cm}^{2}$.Thus the addition of the accelerator GO or GO-PPy in phosphate baths could obviously improve $E_{\text {corr }}$ and decrease $i_{\text {corr }}$. According to Table 2, GP-0.8 had the largest $E_{\text {corr }}$ and the lowest 
$i_{\text {corr }}$ compared with other specimens, which indicated its best corrosion resistance performance.

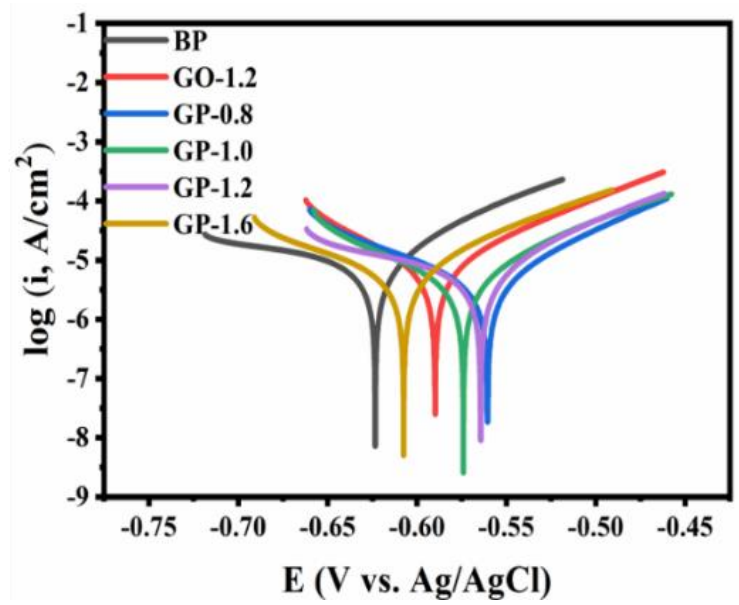

1 Tafel curves of specimens obtained from phosphating bath.

When the concentration of GO-PPy in the phosphating bath raised up to $1.6 \mathrm{~g} / \mathrm{L}, E_{\text {corr }}$ for GP-1.6 decreased and $i_{\text {corr }}$ for GP1.6 increased evidently, which indicated that excessive GO-PPy in the phosphating bath was not conducive to increase $E_{\text {corr }}$ or decrease $i_{\text {corr }}$ of the specimens, and its corrosion resistance ability became worse. This excellent anticorrosion property was also evident by the minimum corrosion rate. According to Table 2 , the corrosion rate of GP- 0.8 was $3.46 \times 10^{-2} \mathrm{~mm} /$ year, which was smaller than that of BP, GO-1.2 and GP-1.6, indicating its best corrosion resistance performance.

\subsection{EIS characteristics}

The corrosion behaviors of phosphate coating are commonly evaluated by EIS measures. Fig. 2 exhibits the Nyquist and Bode plots of all phosphate coatings immersed in $3.5 \mathrm{wt} \% \mathrm{NaCl}$ solution. as depicted in Fig. 2a, the Nyquist plots of all the specimens exhibited a flat semicircle arc, which were associated with frequency dispersion due to defects in the coatings. ${ }^{[22]} \mathrm{As}$ the concentration of GO-PPy increased in phosphate bath, the size of semicircle diameter was enlarged until acquiring the largest diameter for GP-1.2 at the concentration of $1.2 \mathrm{~g} / \mathrm{L}$, after which the semicircle diameter diminished again. Generally, the larger size of semicircle diameter, the higher polarization resistance. ${ }^{[23]}$ Therefore, GP-1.2 had the largest semicircle diameter, indicating excellent corrosion resistance compared with other specimens. Moreover, semicircle diameters of the various GP specimens were larger than that of GO-1.2 or BP specimen, which indicated that GO-PPy obviously accelerated the phosphate progress of phosphate coatings. This might be attributed to the increase of interlayer spacing owing to hydrophilic PPy functionalized CO, and improved dispersion ability of the agglomerated GO in phosphate baths. In general, the value of impedance modulus at lowest frequency $\left(\mathrm{Z}_{0.01 \mathrm{~Hz}}\right)$ is applied to assess the protective ability of the coatings. From Fig. $2 \mathrm{c}$, it was clearly found that the addition of GO-PPy into phosphate bath led to the improvement of $|\mathrm{Z}|_{0.01 \mathrm{~Hz}}$ for all GP specimens compared to the BP specimen, whereas the $|\mathrm{Z}|_{0.01 \mathrm{~Hz}}$ for the GP-1.2 was highest compared with other specimens, revealing its best anticorrosion performance.

Phase angle $(-\theta)$ is another important parameter, showing the change of integrity coatings during immersion in corrosive electrolyte. ${ }^{[24,25]}$ Generally, A larger phase angle represents a denser coating. As shown in Fig. $2 b$, the $-\theta$ of BP appeared at low frequency, and was significantly lower than that of other specimens, which indicated that the coating had serious delamination or defects, and lost protective ability. Moreover, GP-1.2 had the highest $-\theta$ compared with other specimens, indicating that it had best corrosion resistance property.

\subsection{Fitting results of EIS measurement}

Based on the EIS results and morphologies of phosphate coatings, Fig. 3 exhibits the fitting equivalent circuit model for the coated steels, where $C P E, R_{c t}$ and $R_{S}$ represented constant phase element, charge transfer resistance and solution resistance, respectively. These fitting results acquired from the equivalent circuit are presented in Table 3 . According to the data of Table 3, a low $C P E$ and high $R_{c t}$ were also acquired for all phosphate coatings.
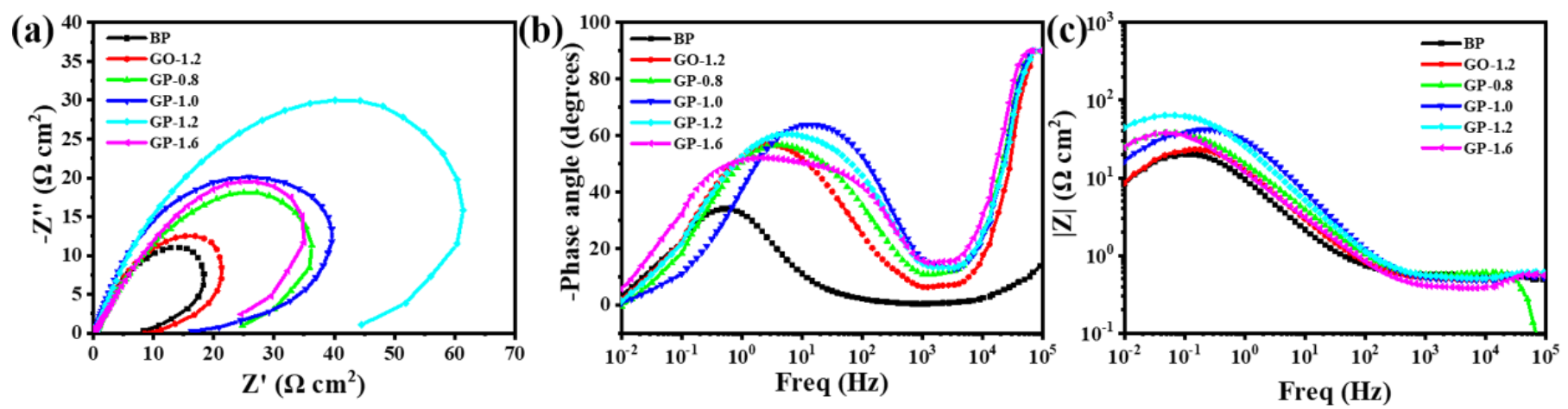

Fig. 2 Nyquist (a) and Bode (b-c) plots of all phosphate coatings immersed in $3.5 \mathrm{wt} \% \mathrm{NaCl}$ solution. 


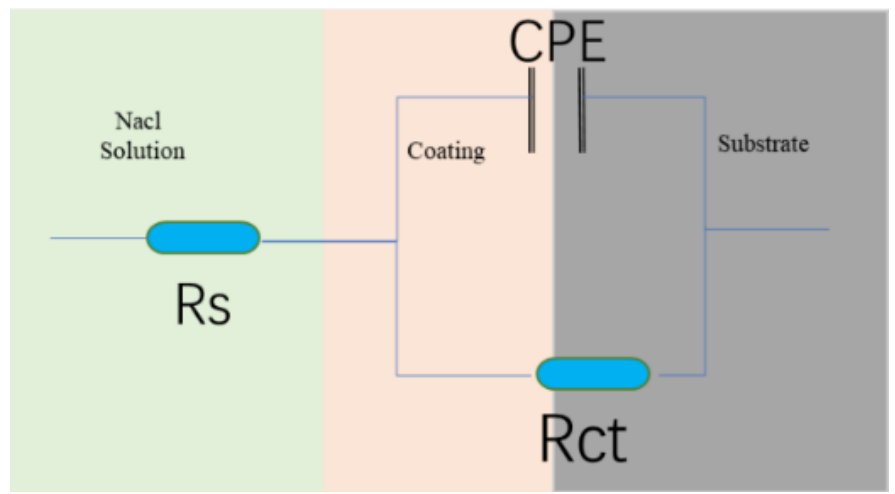

Fig. 3 Equivalent circuit model of the phosphate coatings.

Furthermore, $R_{c t}$ for phosphate coatings first increased with increasing the concentration of GO-PPy in phosphating bath, and reached the maximum at the concentration of $1.2 \mathrm{~g} / \mathrm{L}$, and then decreased again. Nevertheless, the $R_{c t}$ for GP-1.6 was still around two times higher than that of BP. The largest $R_{c t}$ for GP-1.2 thereby revealed that it showed the best corrosion resistance performance than other specimens, which was consistent with the results of EIS measures.

\subsection{XRD characterization of phosphate coating}

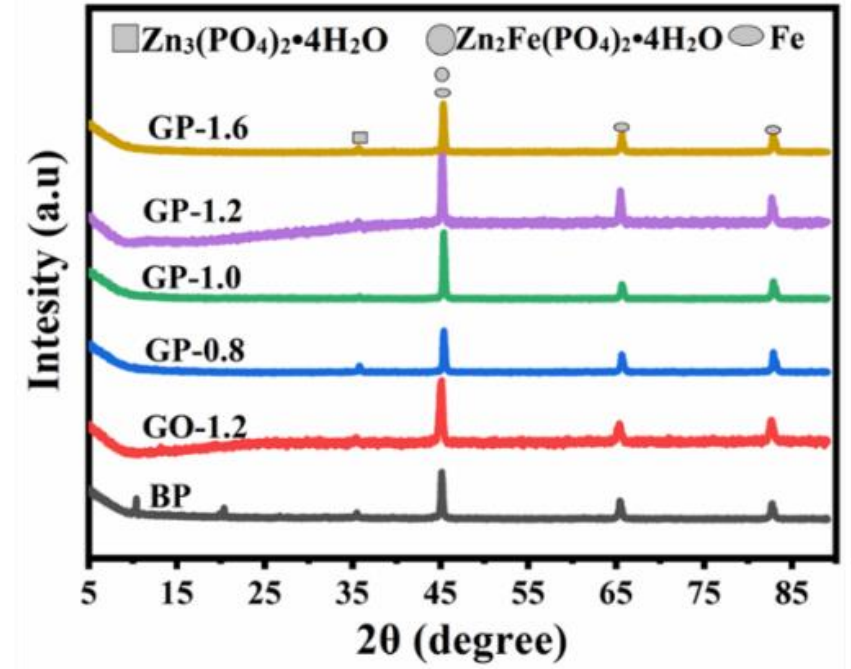

The phase composition of various phosphate coatings was characterized by XRD. The corresponding results are shown in Fig. 4. The peak at $2 \theta=36^{\circ}$ was attributed to the crystal structure of $\mathrm{Zn}_{3}\left(\mathrm{PO}_{4}\right)_{2} \cdot 4 \mathrm{H}_{2} \mathrm{O}(\mathrm{JCDF} \# 37-0465)$, and the peak at $2 \theta=45^{\circ}$ was attributed to the crystal structure of $\mathrm{Zn}_{2} \mathrm{Fe}\left(\mathrm{PO}_{4}\right)_{2} \cdot 4 \mathrm{H}_{2} \mathrm{O}$ (JCDF\#29-1427). Other peaks at $2 \theta=45^{\circ}, 65^{\circ}$ and $84^{\circ}$ were attributed to the metal of Fe.

\subsection{Morphology characteristic of phosphate crystal in the phosphating process}

The morphology characteristic of phosphate crystals on the surface of the specimens were carried out by FESEM. The microstructure morphologies of phosphate crystals at different phosphating stages are shown in Fig. 5. The phosphate crystals on the specimen surface crystallized and grew with the prolongation of phosphating time, finally formed a dense phosphate coating on the substrate surface, which was used to protect the metal substrate from corrosion. As GO-PPy was added into the phosphating baths, the phosphating processes of these specimens were accelerated, and formed the dense phosphate coatings, which was the most obvious for GP-1.2.

In the early phosphate stage ( $1 \mathrm{~min})$, phosphate crystals were hardly observed for BP. As GO-PPy was added into phosphating bath, the crystals were observed obviously at this stage. As the phosphating time reached $7 \mathrm{~min}$, fine phosphate crystals were observed in almost all effective regions for GP-1.2 specimen. While only a small amount of crystals was observed on BP specimen. When phosphating processes were basically completed (20 min), the surface of GP-1.2 was denser, and the crystal clusters were connected more tightly compared with other specimens, revealing its best corrosive resistance property. Additionally, the addition of GO-PPy into the phosphating bath increased the crystalline coverage degree by reducing the size of phosphate crystals in the phosphate coating, which suggested that GO-PPy was beneficial for phosphate nucleation and the formation of smaller and denser crystals on the surface of the specimens.

Fig. 4 XRD spectrums of the specimens after immersed in phosphate baths.

Table 2. Polarization parameters obtained from potentiodynamic polarization curves.

\begin{tabular}{lccccc}
\hline Sample & $\begin{array}{c}E_{\text {corr }} \\
(\mathrm{mV} v \mathrm{Ag} / \mathrm{AgCl})\end{array}$ & $\begin{array}{c}i_{\text {corr }} \\
\left(\mu \mathrm{A} / \mathrm{cm}^{2}\right)\end{array}$ & $\begin{array}{c}b_{a} \\
(\mathrm{mV} / \mathrm{dec})\end{array}$ & $\begin{array}{c}b_{c}(\mathrm{mV} / \mathrm{de} \\
\mathrm{c})\end{array}$ & $\begin{array}{c}\text { Corrosion rate } \\
(\mathrm{mm} / \text { year })\end{array}$ \\
\hline BP & -623 & 5.72 & 51 & 110 & $6.73 \times 10^{-2}$ \\
GO-1.2 & -590 & 5.16 & 58 & 60 & $6.08 \times 10^{-2}$ \\
GP-0.8 & -561 & 2.94 & 54 & 74 & $3.46 \times 10^{-2}$ \\
GP-1.0 & -574 & 3.16 & 55 & 70 & $3.73 \times 10^{-2}$ \\
GP-1.2 & -564 & 3.79 & 53 & 100 & $4.46 \times 10^{-2}$ \\
GP-1.6 & -608 & 3.91 & 56 & 79 & $4.61 \times 10^{-2}$ \\
\hline
\end{tabular}




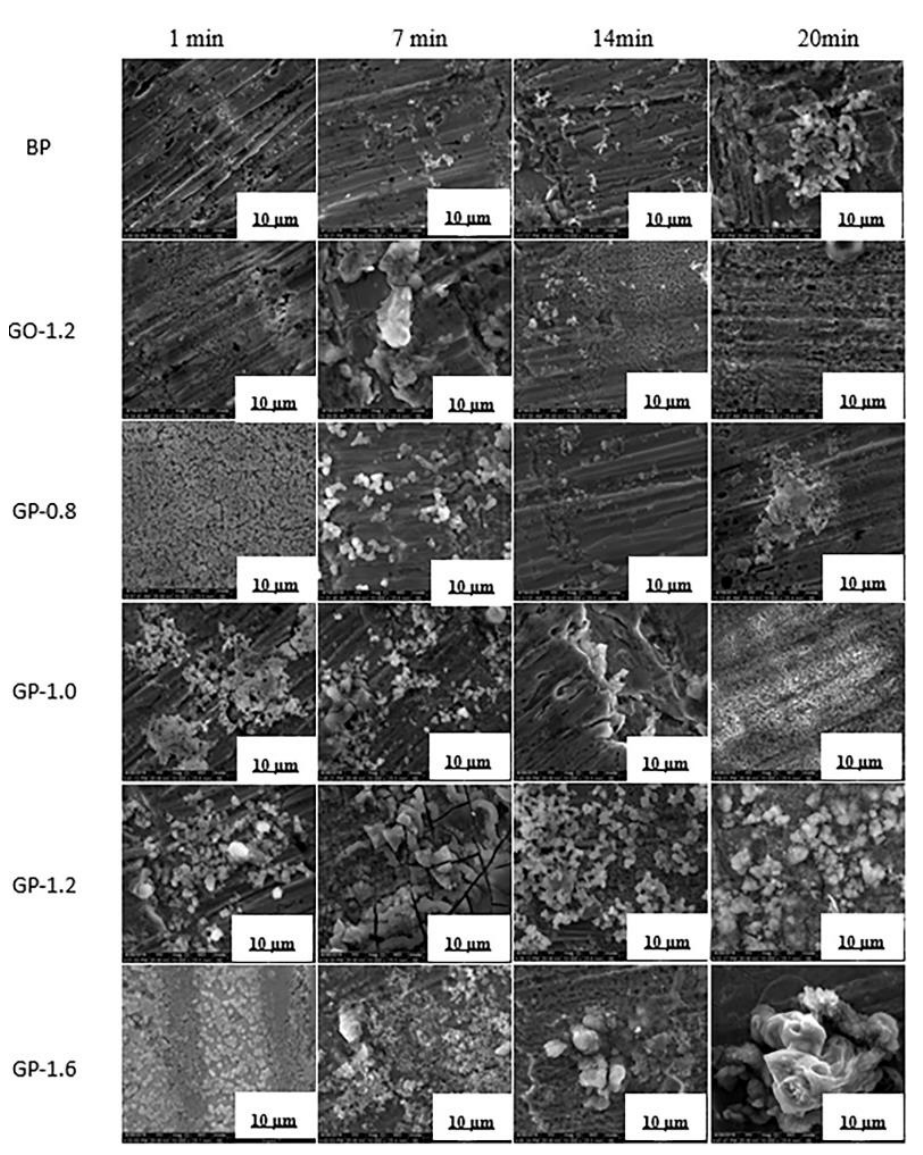

Fig. 5. FESEM images of phosphate coatings with various concentrations of GO-PPy and different phosphating time.

The GO-PPy in the phosphating bath had an obvious impact on the decrease in the size of phosphate crystals which were covered on specimen and raised the amount of micro-cathode points which could accelerate the reaction of hydrogen evolution. ${ }^{[26]}$ This rapidly consumed free phosphoric acid in phosphating bath and increased the $\mathrm{pH}$ values at interfaces between the specimen and phosphating bath. The soluble primary phosphate was transformed into insoluble tertiary phosphate because of the increase of $\mathrm{pH}$ value, and then deposited on mild steel substrate surface. ${ }^{[27]}$

Throughout the phosphating process, the morphologies of phosphate crystals had changed from plate-like to slab-like as GO-PPy was added into phosphating bath, phosphate crystals covered the mild steel surface showing the most denser and uniform at the concentration of $1.2 \mathrm{~g} / \mathrm{L} \mathrm{GO}-\mathrm{PPy}$. Unfortunately, as the concentration of GO-PPy reached $1.6 \mathrm{~g} / \mathrm{L}$, excessive GOPPy nanosheets would overlap the steel substrate surface and phosphate crystals were no longer uniform and compact, and large crystals appeared, which reduced the crystal coverage degree on the surface of mild steel.

\subsection{Mechanism of phosphating process}

The phosphating mechanism of traditional phosphating bath had been widely researched. ${ }^{[23,28]}$ When exposed to phosphate bath, the mild steel was first transformed into iron ions and $\mathrm{H}_{2}$ was released at the initial stage of phosphating process as shown in Equation (1).

$$
\mathrm{Fe}+2 \mathrm{H}^{+} \rightarrow \mathrm{Fe}^{2+}+\mathrm{H}_{2} \uparrow
$$

The $\mathrm{pH}$ at the phosphating bath/mild steel interface raised because of the transition from hydrogen ions to $\mathrm{H}_{2}$, which accelerated the ionization of phosphoric acid as depict in (2) reaction, and thus resulted in $\mathrm{PO}_{4}{ }^{3-}$. As (1) and (2) continued forward, the content of $\mathrm{PO}_{4}{ }^{3+}$ and $\mathrm{Fe}^{2+}$ reached saturated. Then, $\mathrm{Fe}^{2+}$ reacted with $\mathrm{PO}_{4}{ }^{3+}$ on the surface of mild steel to form insoluble ferrous phosphate as follows.

$$
\begin{gathered}
\mathrm{H}_{3} \mathrm{PO}_{4} \rightarrow \mathrm{H}_{2} \mathrm{PO}_{4}^{-}+\mathrm{H}^{+} \rightarrow \mathrm{HO}_{4}^{2-}+2 \mathrm{H}^{+} \rightarrow \mathrm{PO}_{4}^{3-}+3 \mathrm{H}^{+} \\
2 \mathrm{PO}_{4}^{3-}+3 \mathrm{Fe}^{2+}+8 \mathrm{H}_{2} \mathrm{O} \rightarrow \mathrm{Fe}_{3}\left(\mathrm{PO}_{4}\right)_{2} \cdot 8 \mathrm{H}_{2} \mathrm{O} \downarrow
\end{gathered}
$$

As the reaction continued, the deposited insoluble phosphate could be crystallized to form phosphate coating. Moreover, phosphate crystals including $\mathrm{Zn}_{3}\left(\mathrm{PO}_{4}\right)_{2} \cdot 4 \mathrm{H}_{2} \mathrm{O}$ and $\mathrm{Zn}_{2} \mathrm{Fe}\left(\mathrm{PO}_{4}\right)_{2} \cdot 4 \mathrm{H}_{2} \mathrm{O}$ covered the specimen surface, which was confirmed by Fig. 4.

$$
\begin{gathered}
\mathrm{Fe}^{2+}+4 \mathrm{H}_{2} \mathrm{O}+2 \mathrm{Zn}^{2+}+2 \mathrm{PO}_{4}^{3-} \rightarrow \mathrm{Zn}_{2} \mathrm{Fe}\left(\mathrm{PO}_{4}\right)_{2} \cdot 4 \mathrm{H}_{2} \mathrm{O} \downarrow \\
4 \mathrm{H}_{2} \mathrm{O}+3 \mathrm{Zn}^{2+}+2 \mathrm{PO}_{4}^{3-} \rightarrow \mathrm{Zn}_{3}\left(\mathrm{PO}_{4}\right)_{2} \cdot 4 \mathrm{H}_{2} \mathrm{O} \downarrow
\end{gathered}
$$

When GO-PPy sheets were introduced into phosphating bath, GO-PPy nanosheets were easy to be absorbed on the surface of mild steel because of its abundant groups and large specific surface area. the absorbed GO-PPy nanosheets activated mild steel surface and increased the number of micro-cathode points. This accelerated the dissociation process of $\mathrm{H}_{3} \mathrm{PO}_{4}$ and the dissolving reaction of mild steel, ${ }^{[29]}$ which promoted the following crystallization reactions. Furthermore, the absorbed GO-PPy on the substrate surface could capture dissolved $\mathrm{Fe}^{2+}$ and $\mathrm{Zn}^{2+}$, then the crystallization reactions including (3), (4) and (5) might be speeded up even at low concentrations of GO-PPy in phosphate baths. Additionally, the conductive PPy could increase the layer spacing owing to the interaction with $\pi-\pi$ bonds, which indicated that more uniformly dispersed nanosheets might be absorbed at phosphating solution/steel interface. As a result, the above-mentioned role had been strengthened.

GO-PPy nanosheets accelerated the phosphating process, and promoted the crystallization of phosphate crystals in the phosphating coating. This could explain many phosphate crystals could be observed and grew up for GP-1.2 at the initial stage of phosphating process. Meanwhile, phosphate crystals were scarcely discovered on the surface of BP. Additionally, the early formed crystals were regarded as new nucleation points to speed up the following crystallization of phosphate crystals and decreased the size of crystals. Then, the maximum number of phosphate crystals was obtained in the early phosphating process at the concentration of $1.2 \mathrm{~g} / \mathrm{L} \mathrm{GO}-\mathrm{PPy}$ and its grain size was the smallest in the completed phosphating stage. 
Table 3. Electrochemical parameters acquired from corresponding EIS results.

\begin{tabular}{cccccc}
\hline Sample & $\mathrm{E}_{\text {corr }}(\mathrm{mVvs.Ag} / \mathrm{AgCl})$ & $R_{s}\left(\Omega \mathrm{cm}^{2}\right)$ & $R_{c t}\left(\Omega \mathrm{cm}^{2}\right)$ & $C P E$ & Chi-Square \\
\hline BP & -623 & 0.7269 & 18.32 & $9.75 \times 10^{-3}$ & $1.91 \times 10^{-1}$ \\
& & & & & \\
GO-1.2 & -590 & 0.7519 & 20.89 & $6.04 \times 10^{-3}$ & $2.51 \times 10^{-1}$ \\
GP-0.8 & -561 & 0.7346 & 35.73 & $1.21 \times 10^{-2}$ & $1.61 \times 10^{-2}$ \\
GP-1.0 & -574 & 0.6991 & 37.28 & $2.12 \times 10^{-3}$ & $2.17 \times 10^{-1}$ \\
GP-1.2 & -564 & 0.7995 & 56.86 & $2.98 \times 10^{-3}$ & $2.44 \times 10^{-1}$ \\
GP-1.6 & -608 & 0.7585 & 32.64 & $5.44 \times 10^{-3}$ & $3.42 \times 10^{-1}$ \\
\hline
\end{tabular}

As exhibited in Fig. 5, when excessive GO-PPy was added into phosphate bath, excessive GO-PPy nanosheets were deposited and overlapped on the steel substrate surface. Then, the dissolution reaction (1) of the iron was suppressed and restricting the reaction $(2 \& 3)$ of phosphoric acid decomposition. Therefore, the insufficient $\mathrm{Fe}^{2+}$ and $\mathrm{PO}^{3-}$ resulted in the crystallization process slowly. This can explain that fewer loaded phosphate crystals covered on the surface of GP-1.6 compared with GP-1.2. As a result, GP-1.2 obtained the most compact and thickest coating with the smallest size of phosphate crystals. Based on the above discussion, as GO-PPy was added, the (4) and (5) reactions of phosphate crystal crystallization were accelerated to form $\mathrm{Zn}_{2} \mathrm{Fe}\left(\mathrm{PO}_{4}\right)_{2} \cdot 4 \mathrm{H}_{2} \mathrm{O}$ and $\mathrm{Zn}_{3}\left(\mathrm{PO}_{4}\right)_{2} \cdot 4 \mathrm{H}_{2} \mathrm{O}$ crystals in phosphating coating. Phosphating baths generated many $\mathrm{Zn}^{2+}$ ions as depicted in Table 1, which were conducive to form $\mathrm{Zn}_{3}\left(\mathrm{PO}_{4}\right)_{2} \cdot 4 \mathrm{H}_{2} \mathrm{O}$ crystals. Additionally, the added excessive GO-PPy nanosheets restricted (1) reaction and $\mathrm{Fe}^{2+}$ ions were inadequate, which led to the gradual decrease in the peak intensities of $\mathrm{Zn}_{2} \mathrm{Fe}\left(\mathrm{PO}_{4}\right)_{2} \cdot 4 \mathrm{H}_{2} \mathrm{O}$.

In brief, the steel specimen in phosphating bath absorbed the added GO-PPy nanosheets and was regarded as the deposited bed to capture the generated metal ions $\left(\mathrm{Zn}^{2+}\right.$ and $\left.\mathrm{Fe}^{2+}\right)$, which could accelerate the reaction of the crystallization reaction. However, excessive GO-PPy nanosheets would overlap the surface of steel substrate and surpassed the dissociation of phosphoric acid and dissolution of irons. Therefore, $\mathrm{Fe}^{2+}$ and $\mathrm{PO}^{3-}$ ions were inadequate, which inhibited the following crystallization reactions. Moreover, hydrophilic PPy functionalized GO improved the dispersion ability in phosphating bath owing to the increase of interlayer spacing, resulting in more uniform nanosheets absorbed on the surface of mild steel compared to GO nanosheets.

\section{Conclusions}

In this paper, GO-PPy was prepared by in-situ process to grow PPy film on the surface of GO, and investigated the probability of using the functionalized $\mathrm{GO}$ as accelerator to accelerate phosphating process on mild steel. Results demonstrated that the addition of GO-PPy into the phosphating bath could accelerate the phosphating process and promote the crystallization of phosphate crystals, acquiring a better corrosion protection. The specific mechanism was that GO-PPy could be absorbed on the mild surface, then acted as sedimentary beds which captured metal ions and promoted the nucleation of phosphate crystals. Moreover, the functionalized GO had a better dispersion in phosphate baths compared to GO, which strengthened the above role. As the concentration of GO-PPy was optimized to be $1.2 \mathrm{~g} / \mathrm{L}$, the specimen possessed the most compact and uniform phosphate crystals, indicating its best corrosion protection performance. However, excessive GO-PPy nanosheets would overlap mild steel surface, which surpassed the dissociation process of phosphoric acid and dissolution process of irons. As a result, $\mathrm{PO}_{4}{ }^{3-}$ and $\mathrm{Fe}^{2+}$ ions were inadequate, which inhibited the following crystallization reactions. But owing to the fact that the co-deposited GO-PPy sheets acted as additional barrier to block the permeation of corrosive medias, the phosphate coatings with high contents of GO-PPy showed stronger corrosion protection compared to pure phosphate coating. Therefore, GO could be used as a new accelerator to apply in the traditional phosphating industry.

\section{Acknowledgments}

This study was supported by Henan provincial science and technology project of 192102210036 and 132102210209.

\section{Conflict of Interest}

There is no conflict of interest.

\section{Supporting Information}

Not Applicable.

\section{References}

[1] B. Ramezanzadeh, A. Ahmadi, M. Mahdavian, Corros. Sci., 2016, 109, 182-205.doi: 10.1016/j.corsci.2016.04.004.

[2] Y. Liu, J. Xu, J. Zhang, J. Hu, Corros. Sci., 2017, 120, 6174.doi:10.1016/j.corsci.2017.01.017.

[3] Z. Zhang, N. Tian, W. Zhang, X. Huang, L. Ruan, L. Wu, Corros. Sci., 2016, 111, 675-689. doi: 10.1016/j.corsci.2016.06.005.

[4] W. Sun, L. Wang, T. Wu, T. Zhu, H. Xie, Y. Pan, G. Liu, $A d v$. Eng. Mater., 2016, 18, 923-931.doi:10.1002/adem.201500494.

[5] T. Narayanan, S. Jegannathan, K. Ravichandran, Prog. Org. Coat., 2006, 55, 355-362, doi: 10.1016/j.porgcoat.2006.01.009

[6] Y. Xie, M. Chen, D. Xie, L. Zhong, X. Zhang, Corros. Sci., 2017, 128, 1-8.doi: 10.1016/j.corsci.2017.08.033.

[7] A. DiGiampaolo, M. Medina, R. Reyes, M. Velez, Surf. Coat. Technol., 1997, 89, 31-37. doi: 10.1016/j.corsci.2017.08.033. 
[8] M. Tamilselvi, P. Kamaraj, M. Arthanareeswari, S. Devikala, [20] Q. Zhu, E. Li, X. Liu, W. Song, Y. Li, X. Wang, C. Liu, J. Selvi, Appl. Surf. Sci., 2015, 332, 12-21. doi: Comps. Part A, 2020, 140, 105488, 10.1016/j.apsusc.2015.01.177.

[9] X. Ding, L. Xue, X. Wang, K. Ding, S. Cui, Y. Sun, M. Li, J. Magn. Magn. Mater., 2016, 416, 247-255, doi: 10.1002/adem.200500095. doi:10.1016/j.porgcoat.2019.105488.

[21] Q. Zhu, E. Li, X. Liu, W. Song, M. Zhao, L. Zi, X. Wang, C. [10] M. Tamilselvi, P. Kamaraj, M. Arthanareeswari, S. Devikala, J.A. Selvi, Appl. Surf. Sci., 2015, 332, 12-21. doi:10.1016/j.apsusc.2015.01.177.

Liu, Prog. Org. Coat., 2020, 130, 105725, Doi:10.1016/j.compositesa.2019.105752

[22] X. Luo, J. Zhong, Q. Zhou, S. Du, S. Yuan, Y. Liu, ACS Appl. Mater. Interfaces., 2018, 10, 18400-18415, doi:10.1021/acsami.8b01982.

[11] F. Fang, J. Jiang, S. Tan, A. Ma, J. Jiang, Surf. Coat. Technol., [23] C. Jiang, G. Xiao, X. Zhang, R. Zhu, Y. Lu, New J. Chem., 2010, 204, 2381-2385, doi:10.1016/j.surfcoat.2010.01.005. 2016, 40, 1347-1353, Doi:10.1039/C5NJ02245B.

[12] B. Ramezanzadeh, H. Vakili, R. Amini, Appl. Surf. Sci., 2015, [24] X. Zheng, J. Feng, Y. Zong, H. Miao, X. Hu, J. Bai, X. Li, J. 327, 174-181, doi:10.1016/j.apsusc.2014.11.167. Mater. Chem. C., 2015,3, 4452-4463, doi:10.1039/C5TC00313J. [13] F. Fang, J. Jiang, S. Tan, A. Ma, J. Jiang, Surf. Coat. Technol., 2010, 204, 2381, doi:10.1016/j.surfcoat.2010.01.005. [25] Y. Wang, F.Q. Gu, L.J. Ni, K. Liang, K. Marcus, S.L. Liu, F. Yang, J.J. Chen, J. Z.S. Feng, Nanoscale, 2017, 9, 18318-18325, [14] J. Paredes, S. Villar-Rodil, A. Martínez-Alonso, M. Tascon, doi: 10.1039/c7nr05951e.

Langmuir.,2008, 24, 10560-10564.doi:10.1021/la801744a.

[26] M. Sheng, Y. Wang, Q. Zhong, H. Wu, H. Lin, Surf. Coat. [15] B. Singh, B. Jena, S. Bhattacharjee, L. Besra, Surf. Coat. Technol., $\quad 2011, \quad 205, \quad 3455-3460, \quad$ doi: Technol., 2013, 232, 475-481, doi: 10.1016/j.surfcoat.2010.12.011.

10.1016/j.surfcoat.2013.06.004.

[27] B.D. Hall, D. Zanchet, D. Ugarte, J. Appl. Cryst., 2000, 33, [16] C. Liu, F. Su, J. Liang, Appl. Surf. Sci., 2015, 351, 889-896, 1335-1341, doi:10.1107/S0021889800010888. doi:10.1016/j.apsusc.2015.06.018.

[17] J. Mondal, A. Marques, L. Aarik, J. Kozlova, A. Simões, V. Sammelselg, Corros. Sci., 2016, 105, 161-169, doi:10.1016/j.corsci.2016.01.013.

[28] H.Y. Su, C.S. Lin, Corros. Sci., 2014, 83, 137-146, doi:10.1016/j.corsci.2014.02.002.

[18] Y. Xie, M. Chen, D. Xie, L. Zhong, X. Zhang, A fast, Corros. Sci., 2017, 128, 1-8, doi:10.1016/j.corsci.2017.08.033.

[19] S. Qiu, W. Li, W. Zheng, H. Zhao, L. Wang, ACS Appl. Mater. Interfaces, 2017, 9, 34294, doi:10.1021/acsami.7b08325.

Publisher's Note: Engineered Science Publisher remains neutral with regard to jurisdictional claims in published maps and institutional affiliations. 